\title{
Mesectodermal leiomyoma of the ciliary body:
} case report

\author{
VALERIE WHITE,' KATHERINE STEVENSON², ALEC GARNER,' \\ AND JOHN HUNGERFORD ${ }^{2}$
}

From the 'Department of Pathology, Institute of Ophthalmology, 17/25 Cayton Street, London EC1V 9AT, and ${ }^{2}$ Moorfields Eye Hospital, City Road, London EC1V 2PD

SUMmaRY The clinical, light microscopical, and electron microscopical features of a mesectodermal leiomyoma of the ciliary body are presented. This exceptionally rare and apparently benign tumour is considered to be of neural crest origin. In the case described the tumour cells were seen to contain thin filaments with focal densities and conspicuous numbers of mitochondria, and smooth muscle protein was demonstrated by immunohistochemical means.

Smooth muscle tumours of the ciliary body are extremely rare. In 1977 and 1978 Jakobiec et al. reported three cases of an unusual 'hybrid' smooth muscle and neuroectodermal tumour of the ciliary body. ${ }^{12}$ They proposed that the unusual neural appearance of this smooth muscle tumour reflected its origin from the neural crest cells that contribute to the formation of bone, cartilage, connective tissue, and smooth muscle in the head and neck region. These neural crest derived tissues have been termed 'mesectoderm', and hence the terminology of Jakobiec et al. for the ciliary body tumour-a mesectodermal leiomyoma. The present report concerns a fourth example of this highly unusual tumour and highlights some histopathological differences from the previously published cases.

\section{Case report}

HISTORY AND CLINICAL COURSE

A previously fit 38-year-old male teacher was noticed to have an apparent iris tumour on routine visit to an optician. Corrected visual acuity was $6 / 12$ right eye, $6 / 5$ left eye. On closer inspection the tumour was seen to be whitish, with overlying blood vessels, and appeared to be located within the ciliary body at 5 to 6 o'clock with some displacement of the iris root adjacent to its anterior edge (Fig. 1). The tumour did

Correspondence to Professor Alec Garner. not invade the angle but pushed against the lens. There was no cataract and the intraocular pressure was normal. Fundus examination after full mydriasis showed a rather more pigmented, ciliary body tumour but no serous retinal detachment. The left eye was normal. An ultrasound examination of the right eye was suggestive of a malignant melanoma of the ciliary body, but the overall clinical appearance was atypical of this tumour. General physical examination and laboratory investigations were normal.

In December 1986, four months after the tumour was first noticed, the patient underwent an iridocyclectomy, with excision of a clear margin of normal ciliary body and iris surrounding the tumour. The postoperative course was uneventful and the patient had 6/12 vision five months after surgery.

PATHOLOGY

The specimen was received in formalin fixative and consisted of a sector of the ciliary body which contained a firm ovoid and whitish tumour measuring $8 \times 7 \times 5 \mathrm{~mm}$.

Light microscopy. Low power examination of haematoxylin and eosin stained sections revealed a well circumscribed tumour of the ciliary body which was situated where the normal ciliary muscle would have been (Fig. 2). It was covered on one surface by the pigmented and non-pigmented ciliary epithelium and blended with normal ciliary muscle on another surface. The tumour consisted of sheets of polygonal 


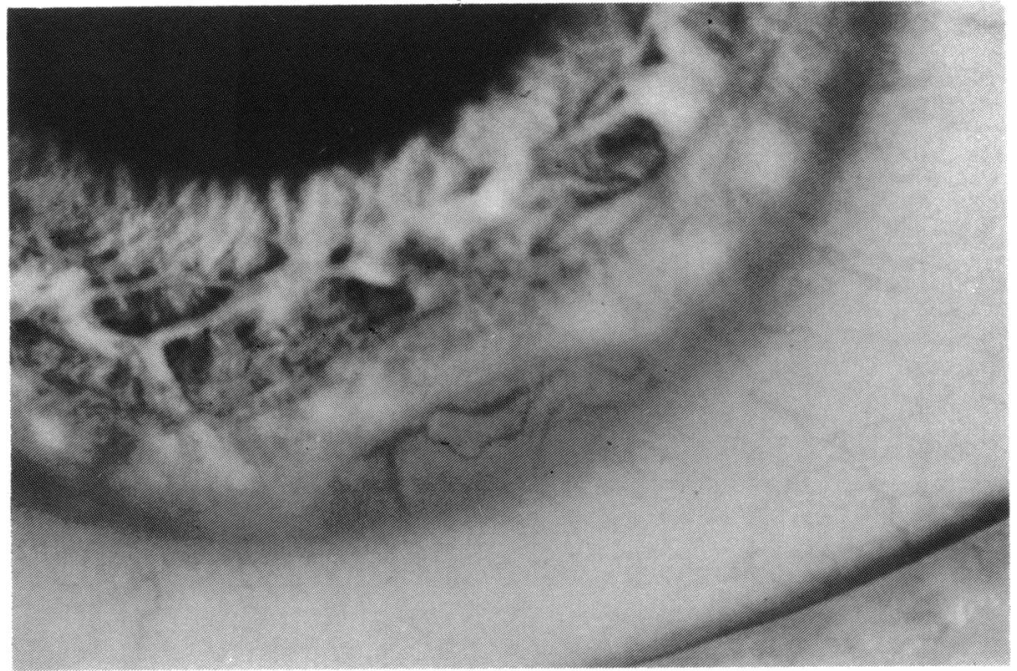

Fig. 1 Clinical photograph of patient's right eye showing vascularised, whitish tumour impinging on and displacing the inferior iris.

cells which tended to become fusiform at the periphery (Fig. 3). The nuclei were central, often with prominent nucleoli, but there were no mitoses. The cytoplasm was abundant and eosinophilic, and whereas in some areas it had an irregular hyaline appearance, in others it appeared more fibrillary (Fig. 4). Large numbers of mast cells were scattered throughout the tumour. There was no staining of the tumour cells by the periodic acid-Schiff (PAS) technique, although PAS positive material was present around many cells. Reticulin staining outlined many cells individually (Fig. 5a). Phosphotungstic acidhaematoxylin (PTAH) and Masson-trichrome stains revealed a few longitudinally orientated fibrils within the more peripherally placed spindle cells. A Fontana-Masson stain for melanin was negative within the tumour. Azure-A staining highlighted the numerous mast cells (Fig. 5b).

Immunohistochemistry. Staining for cytokeratin, glial fibrillary acidic protein (GFAP), S100 protein, and desmin was carried out by a standard three-stage immunoperoxidase technique. There was no staining for cytokeratin and GFAP. Staining for $\mathrm{S} 100$ protein was present in the overlying neuroepithelium and melanocytes trapped within the ciliary muscle, but was absent within the tumour. Antiserum against desmin reacted positively with both the normal ciliary muscle and the tumour cells.

Transmission electron microscopy. Low power magnification revealed angular and polygonal cells, many with blunt, irregular processes (Fig. 6a). Blood vessels were scanty, but numerous mast cells were

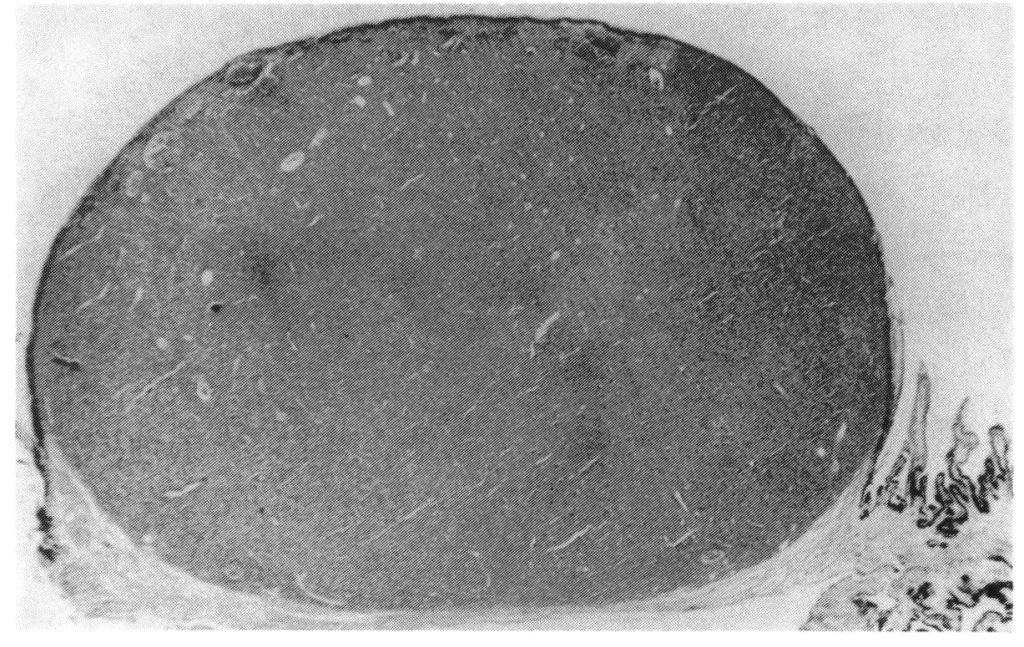

Fig. 2 Low power photomicrograph to show placement of tumour where normal ciliary muscle would have been. It is covered by normal ciliary epithelium and blends into the surrounding ciliary smooth muscle. $H$ and $E, \times 15 \cdot 5$. 
Fig. 3 Cells of the tumour are polygonal centrally, but tending to become fusiform at the periphery. $H$ and $E, \times 120$.

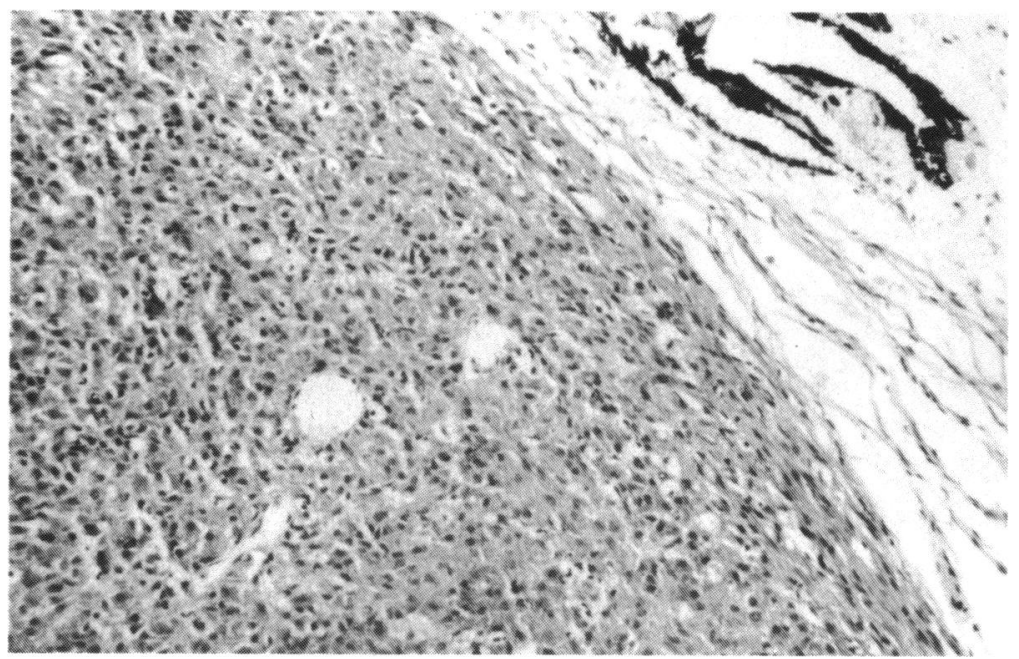

visible. Nuclei were pale with small clumps of heterochromatin and prominent nucleoli (Fig. $6 b)$. The cytoplasm was about equally filled with abundant mitochondria and longitudinally placed thin filaments (Fig. 6c). The mitochondria were often densely packed and abnormally shaped, with occasional tubular forms (Figs. 7a and b), while the thin tained irregularly placed focal densities (Fig. 7c). Only occasional Golgi bodies and endoplasmic reticulum were present. One cilium was seen. Each cell was surrounded by an external lamina which was focally interrupted and focally duplicated. Occasional poorly formed junctions were present (Fig. filaments measured 4-8 nm in diameter and con-

Fig. 4 The nuclei are round, often with prominent nucleoli. Cytoplasm is abundant, eosinophilic and hyaline in some areas, while fibrillary in others. $H$ and $E, \times 450$ ).

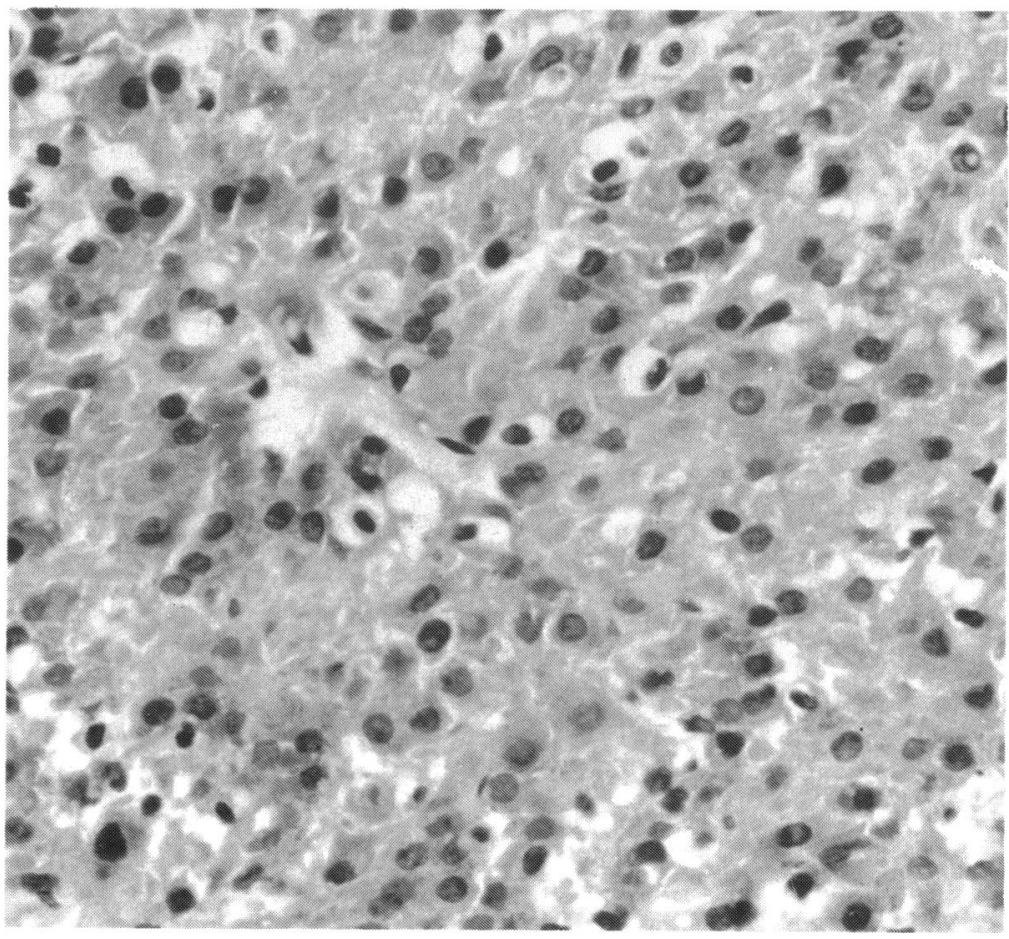



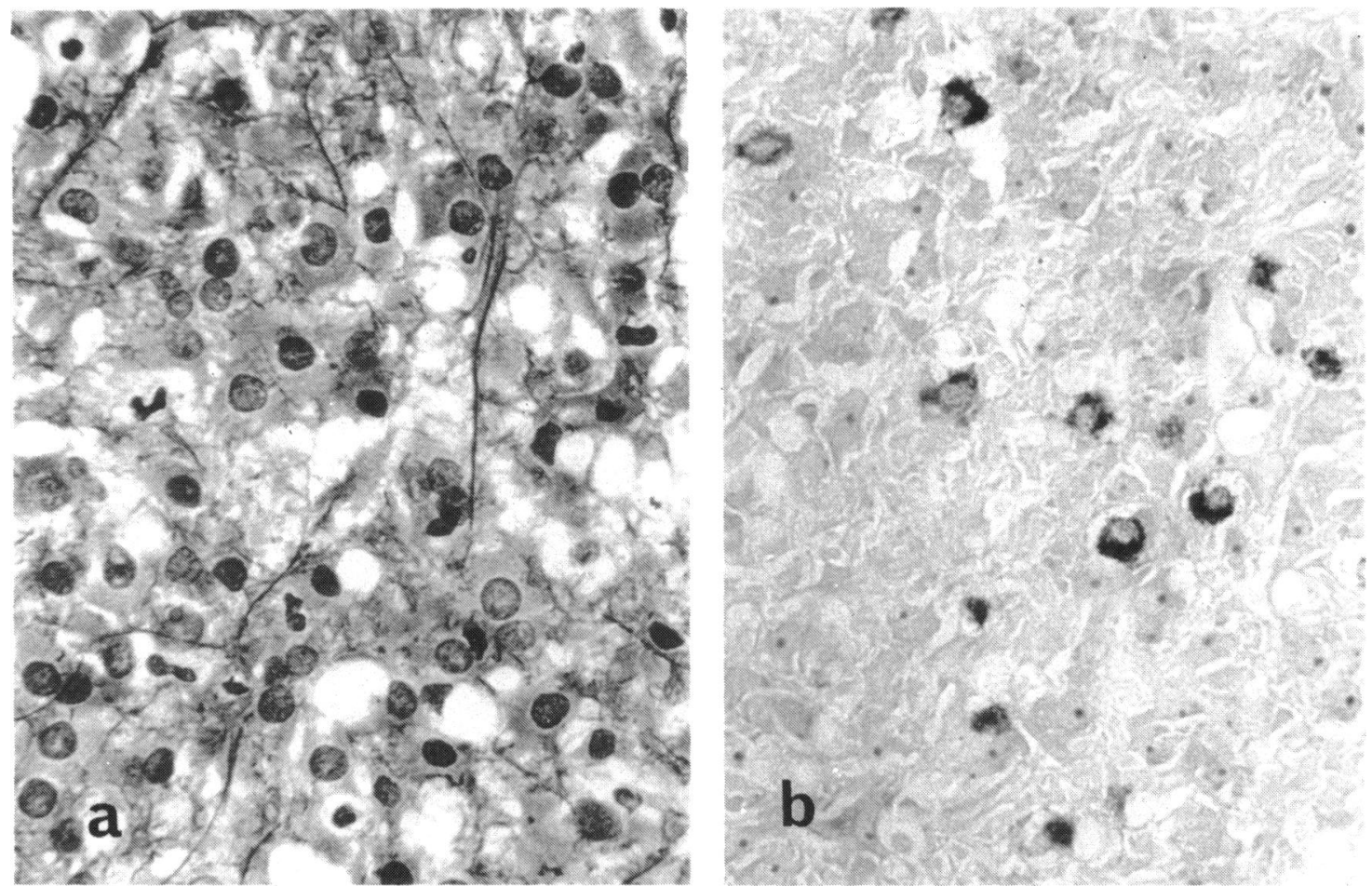

Fig. 5 a: Reticulin outlining of individual cells. Reticulin stain, $\times 450$. b: Large numbers of mast cells are scattered throughout the tumour. Azure- $A, \times 450)$.

6d). No melanosomes, neurotubules, neuronal wrappings, dense core granules, well-formed desmosomes, or pinocytotic vesicles were seen.

\section{Discussion}

Light microscopic differential diagnosis of this unusual tumour included epithelioid leiomyoma, amelanotic naevus or well differentiated melanoma, peripheral nerve tumour, paraganglioma or haemangiopericytoma. The diagnosis of a type of leiomyoma was supported by the electron microscopic demonstration of thin filaments with focal densities and the merging of the tumour with the normal musculature of the ciliary body. The demonstration of desmin by immunohistochemistry constituted further evidence of a muscle tumour. The conspicuously numerous mitochondria raised the possibility of an oncocytoma, but this was not considered to be substantiated either by the position of the tumour below the ciliary epithelium, within the ciliary muscle, or by the lack of epithelial features such as tight junctions and well formed desmosomes on electron microscopy.

In 1977 Jakobiec et al. described two cases of an unusual tumour of the ciliary body which they termed a mesectodermal leiomyoma. ${ }^{1}$ The light microscopic appearances of their cases had led them to think that they were neural tumours, in one case of glial or ganglionic origin and in the other case of peripheral nerve origin. On electron microscopy they found thin cytoplasmic filaments with focal fusiform densities and focal and multilaminated external lamina, features of smooth muscle differentiation. ${ }^{3}$ The fibrillary appearance was given by tangled cell processes containing thin filaments with focal densities. They postulated that these 'hybrid' smooth muscle and neural tumours could develop owing to the origin of most of the ocular and periocular supporting tissues from the neural crest. ${ }^{4}$ Experiments in birds have revealed that only the external ocular muscles and vascular endothelia arise from true mesoderm, while most of the other so called 'mesodermal' tissues, including the smooth muscle of the ciliary body, arise from the neural crest. ${ }^{5}$ In 1978 Jakobiec and Iwamoto reported a similar tumour of the ciliary body which was associated with a naevus, further evidence of a neural crest origin. ${ }^{2} \mathrm{~A}$ case of presumed mesectodermal leiomyosarcoma of the antrum which invaded the orbit has also been reported. ${ }^{6}$ 

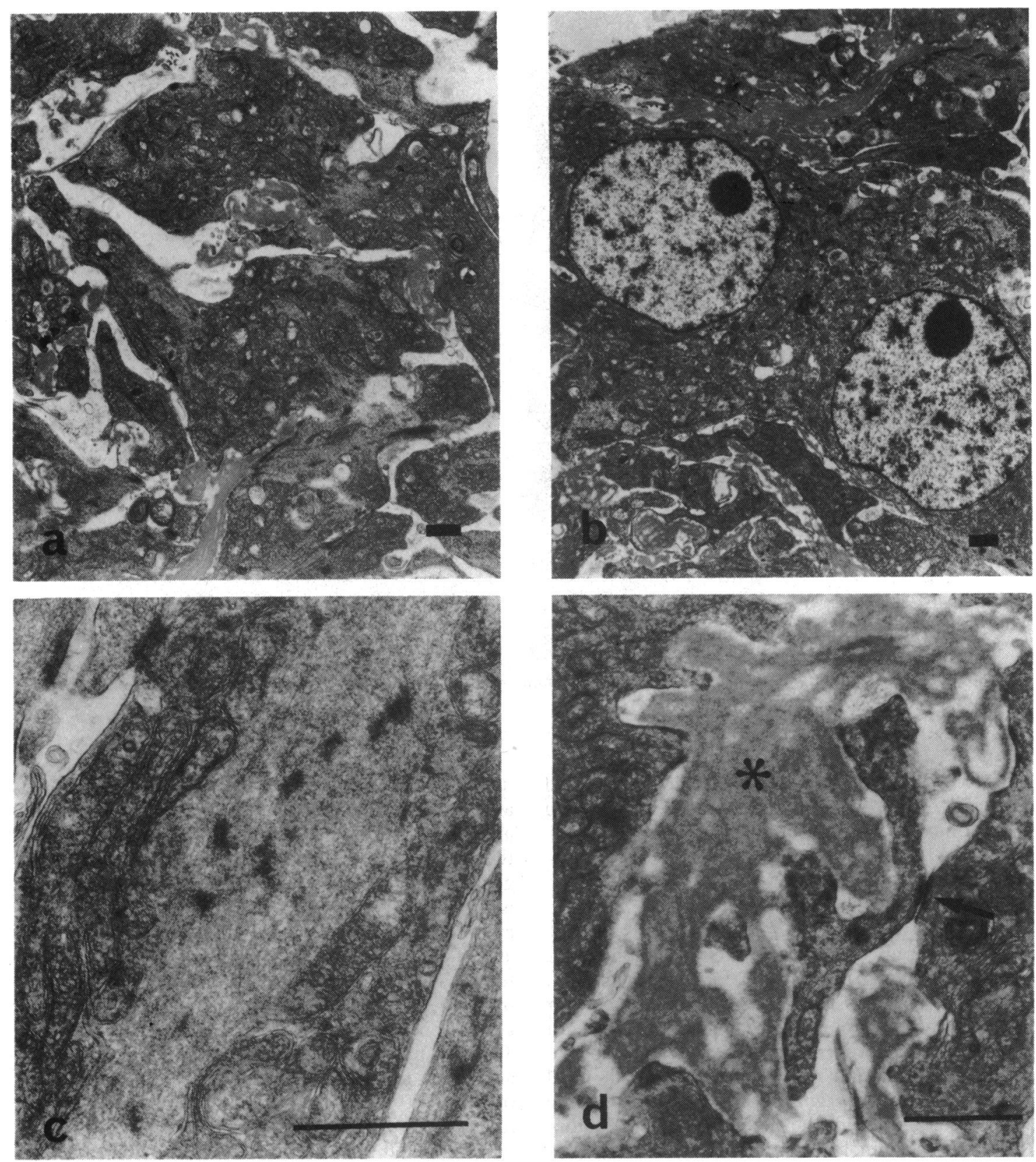

Fig. 6 a: Low magnification electron micrograph to show angular cells with blunt irregular processes. $\times 5000$. b: Nuclei are round and pale with prominent nucleoli. $\times 4000$. $\mathrm{c}$ : Cytoplasm is about equally filled with thin filaments and mitochondria. $\times 25000$. d: Focally duplicated external lamina (asterisk), and poorly formed junctions are present (arrow). $\times 17000$. Bar markers $=1.0 \mu \mathrm{m}$.

The light microscopic appearance of the present case is not suggestive of a tumour of neural origin, and the most prominent feature is the many abnormal mitochondria. Although Jakobiec et al. in their second case comment on numerous degenerated mitochondria, they do not display many in the published electron micrograph. ${ }^{1}$ Oncocytic cells in the thyroid, which are distinguished by a cytoplasm 

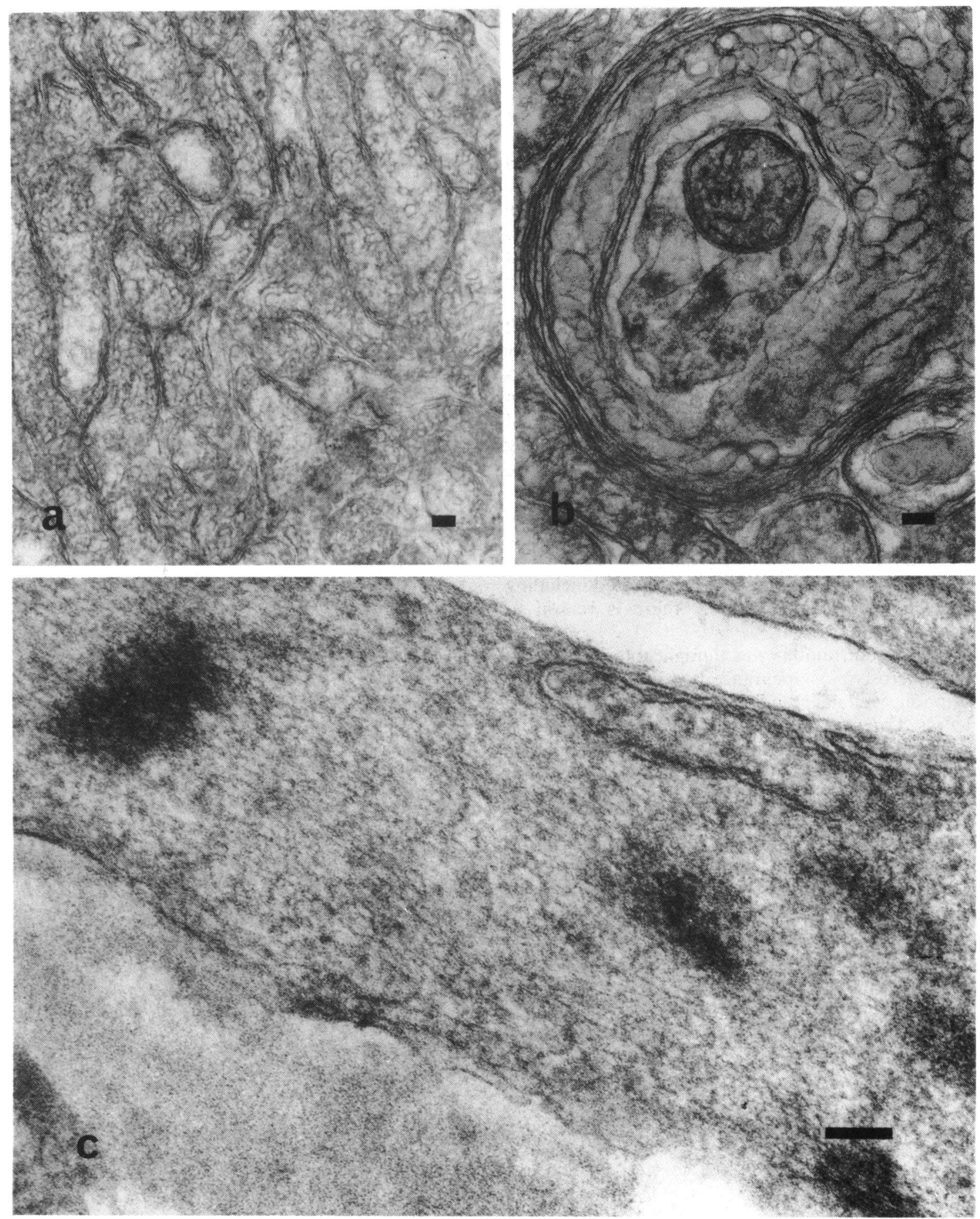

Fig. 7 a: Densely packed mitochondria. $\times 34$ 000. b: An abnormal appearing mitochondrion. $\times 50000$. c: Cell process containing thin filaments with scattered focal densities. $\times 100000$. Bar markers $=0 \cdot 1 \mu \mathrm{m}$.

full of mitochondria, have been shown to contain increased amounts of the oxidative enzymes isocitrate dehydrogenase, succinate dehydrogenase, and cytochrome oxidase, and are thought to reflect organelle hyperplasia in the face of decreased cellular function. ${ }^{7}$ Whether this increase in oxidative enzymes occurs in smooth muscle cells is unknown.

The similarities between the present case and those 
previously reported override the differences and include the round pale nuclei with prominent nucleoli, eosinophilic fibrillary background, blending of the tumour into the normal ciliary muscle, numerous mast cells, cytoplasmic fibrils on PTAH staining, reticulin outlining of single cells, and the thin cytoplasmic filaments with focal densities seen on electron microscopy. Micropinocytotic vesicles, a usual feature of smooth muscle cells, may be absent as in this case, and depend on the physiological state of the cell. ${ }^{3}$

Meyer et al. published the first case of a spindle cell leiomyoma of the ciliary body to be studied by electron microscopy. ${ }^{8}$ Light microscopic findings were characteristic of leiomyomas seen elsewhere in the body. Electron microscopy showed bundles of thin filaments with focal densities orientated along the long axis of the cells, micropinocytotic vesicles, and external laminae. Smooth muscle tumours occurring in other ocular sites have been reported in the choroid ${ }^{9}$ and the orbit, ${ }^{10-12}$ with electron microscopic verification. Although according to Green no leiomyomas of the iris have been reported including electron microscopic studies, ${ }^{13}$ there is reason to believe that they occur. ${ }^{14}$

The present tumour was thought to be benign on light microscopic appearance because of its circumscription, cellular regularity, and lack of mitotic figures. Two of the three reported cases of Jakobiec $e t$ al. have been followed up for 15 years after enucleation and nine years after iridocyclectomy, with no residual or metastatic disease. ${ }^{12}$ Follow-up was not reported in the third case.

This case also highlights the dilemma for the clinician when faced with a patient with good vision and a presumptive diagnosis of a malignant melanoma. Should the patient be treated with conservative or radical surgery? We would suggest caution when faced with a tumour in any way atypical on clinical examination and which is also amenable to local excision. In this case the rather whitish appearance of the tumour and the lack of any sentinel vessels and angle involvement influenced the decision to perform local excision.

In summary, we report a case of an extremely rare tumour of the ciliary body, having features of both neurectodermal tissue and smooth muscle. We believe this tumour is correctly termed a mesectodermal leiomyoma.

Dr Valerie White is the recipient of a fellowship award from the Medical Research Council of Canada.

\section{References}

1 Jakobiec FA, Font RL, Tso MOM, Zimmerman LE. Mesectodermal leiomyoma of the ciliary body. Cancer 1977; 39: 2102-13.

2 Jakobiec FA, Iwamoto T. Mesectodermal leiomyoma of the ciliary body associated with a nevus. Arch Ophthalmol 1978; 96: $692-5$.

3 Ghadially FN. Diagnostic electron microscopy of tumours. 2nd ed. London: Butterworths, 1985: 198-201.

4 Noden DM. Periocular mesenchyme: neural crest and mesodermal interactions. In: Jakobiec FA, ed. Ocular anatomy, embryology and teratology. Philadelphia: Harper and Row, 1982: ch. 3 .

5 Johnston MC, Noden DM, Hazelton RD, Coulombre JL, Coulombre AJ. Origins of avian ocular and periocular tissues. Exp Eye Res 1979; 29: 27-43.

6 Jakobiec FA, Mitchell JP, Chauhan PM, Iwamoto T. Mesectodermal leimyosarcoma of the antrum and orbit. Am J Ophthalmol 1978; 85: 51-7.

7 Kendall CH, McCluskey E, Naylor J, Eagles M. Oxyphil cells in thyroid disease: a uniform change? J Clin Pathol 1986; 39: 90812.

8 Meyer SL, Fine BS, Font RL, Zimmerman LE. Leiomyoma of the ciliary body. Am J Ophthalmol 1968; 66: 1061-8.

9 Jakobiec FA, Witschel H, Zimmerman LE. Choroidal leiomyoma of vascular origin. Am J Ophthalmol 1976; 82: 205-12.

10 Jakobiec FA, Jones IS, Tannenbaum M. Leiomyoma. An unusual tumour of the orbit. BrJ Ophthalmol 1973; 57: 825-31.

11 Jakobiec FA, Howard GM, Rosen M, Wolff M. Leiomyoma and leiomyosarcoma of the orbit. Am J Ophthalmol 1975; 80: 102842.

12 Sanborn GE, Valenzuela RE, Green WR. Leiomyoma of the orbit. Am J Ophthalmol 1979; 87: 371-5.

13 Green WR, Uveal tract, Tumors. In: Spencer WH, ed. Ophthalmic pathology. Philadelphia: Saunders, 1986; 3: 1563.

14 Ashton N. Primary tumours of the iris. Br J Ophthalmol 1964; 48: $650-68$.

Accepted for publication 24 September 1987. 